GEOPHYSICAL RESEARCH LETTERS, VOL. 17, NO. 3, PAGES 287-290, MARCH 1990

\title{
STABILITY OF THE MARTIAN ATMOSPHERE: POSSIBLE ROLE OF HETEROGENEOUS CHEMISTRY
}

\author{
S. K. Atreya
}

The University of Michigan, Ann Arbor

J. E. Blamont

Service d'Aeronomie du C.N.R.S., France

Abstract. A new hypothesis is proposed for recycling Martian $\mathrm{CO}$ to $\mathrm{CO}_{2}$. The same hypothesis can satisfactorily explain the recently observed depletion in $\mathrm{CO}$ in the middle atmosphere of Mars. The mechanism involves oxidation of carbon monoxide through heterogeneous chemistry in the presence of aerosols. It is further suggested that $\mathrm{H}_{2} \mathrm{O}$ ice aerosols in the atmosphere of Mars are particularly effective in this process. The thrust for suggesting this mechanism came from the extensive presence of aerosols in the Martian atmosphere detected by the Auguste-Spectrophotometer Interferometer experiment on the Phobos spacecraft, combined with similar results from earlier missions, the detection of relatively low $\mathrm{CO}$ mixing ratios in the low to middle atmosphere by the Infrared Spectrometer experiment on the Phobos spacecraft, and the fact that earlier proposed mechanisms for recycling $\mathrm{CO}_{2}$ require either unacceptably high values of the eddy diffusion coefficient or a high water vapor abundance in the middle atmosphere of Mars. The mechanism proposed in this paper might have an analog in the Antarctic ozone hole problem, and it points out a need for laboratory measurements of appropriate sticking coefficients and rate constants.

\section{Introduction}

The abundance of carbon dioxide in the atmosphere of Mars is known to be stable except for seasonal changes of the order of $\sim 30 \%$, caused by its deposition onto and evaporation from the polar ice cap reservoir. Yet $\mathrm{CO}_{2}$ is photodissociated below $2200 \AA$ at an average rate of $2 \times 10^{12} \mathrm{~cm}^{-2} \mathrm{~s}^{-1}$, i.e.,

$$
\mathrm{CO}_{2}+\mathrm{hv}-\cdots+-\longrightarrow \mathrm{CO}+\mathrm{O}
$$

In the absence of an effective recycling mechanism, all of the $\mathrm{CO}_{2}$ in the Martian atmosphere would have been converted to its photolysis products, $\mathrm{CO}$ and $\mathrm{O}$, in approximately 3000 years (certainly less than 10,000 years when variations and uncertainties in the solar flux and total atmospheric $\mathrm{CO}_{2}$ inventory are included). Moreover, the present day mixing ratios of $\mathrm{CO}$ and $\mathrm{O}_{2}(-0.1 \%$ each) would have been attained in 3-6 years. $\mathrm{O}_{2}$ is formed on recombination of the $\mathrm{O}$ atoms, i.e.,

$$
\mathrm{O}+\mathrm{O}+\mathrm{M}-\cdots \mathrm{O}_{2}+\mathrm{M}
$$

where $\mathrm{M}$ represents the background gas $\mathrm{CO}_{2}$. It is also known that $\mathrm{CO}$ and $\mathrm{O}_{2}$ levels are stable as well, i.e., their abundances do not continue to build up. It is apparent that $\mathrm{CO}_{2}$ must be recycled efficiently in the atmosphere of Mars. Direct three-body recombination is, however, spin forbidden, i.e.,

Copyright 1990 by the American Geophysical Union.

Paper number 90GL00322.

0094-8276/90/90GL-00322\$03.00

$$
\mathrm{CO}+\mathrm{O}+\mathrm{M}------>\mathrm{CO}_{2}+\mathrm{M}
$$

The rate constant of $R 3$ is a factor of 40,000 smaller than that of $\mathbf{R 2}$.

Two mechanisms were suggested in the pre-Viking era for stabilizing the level of $\mathrm{CO}_{2}$ in the Martian atmosphere, both based on catalytic oxidation of $\mathrm{CO}$ involving an $\mathrm{HO}_{\mathrm{x}}$ cycle. In both mechanisms, relatively large values of the eddy diffusion coefficient $\mathrm{K}$, exceeding the terrestrial values by factors of 100 to 10,000 at similar atmospheric density levels, are required. Furthermore, one mechanism requires a large abundance of water vapor as well. We first discuss briefly these mechanisms and their shortcomings. Following this, an alternate hypothesis involving heterogeneous chemistry on aerosols (preferably ice aerosols) is proposed. Supporting observational results are included.

Mechanism 1: Large $\mathrm{K}$ and Moderate $\mathrm{H}_{2} \mathrm{O}$ (McElroy and Donahue, 1972)

$\mathrm{CO}$ molecules produced in the photodissociation of $\mathrm{CO}_{2}$ (R1) and in the $\mathrm{CO}_{2}^{+}$charge exchange reaction $\mathrm{R} 5$--

$$
\begin{array}{lll}
\mathrm{CO}_{2}+\mathrm{hv} & \rightarrow-\rightarrow \mathrm{CO}_{2}^{+}+\mathrm{e} \\
\mathrm{CO}_{2}^{+}+\mathrm{O} & \rightarrow-\rightarrow \mathrm{O}_{2}^{+}+\mathrm{CO}
\end{array}
$$

-- react with hydroxyl radicals to recycle $\mathrm{CO}_{2}$ as follows:

$$
\begin{array}{lll}
\mathrm{CO}+\mathrm{OH} & \cdots & \mathrm{CO}_{2}+\mathrm{H} \\
\mathrm{H}+\mathrm{O}_{2}+\mathrm{M} & \cdots & \mathrm{HO}_{2}+\mathrm{M} \\
\mathrm{HO}_{2}+\mathrm{O} & \cdots & \mathrm{OH}+\mathrm{O}_{2}
\end{array}
$$

Net: $\quad \mathrm{CO}+\mathrm{O}+\mathrm{M} \quad \ldots \rightarrow \mathrm{CO}_{2}+\mathrm{M}$

The $\mathrm{OH}$ radicals in $\mathrm{R} 6$ are produced in the photolysis of $\mathrm{H}_{2} \mathrm{O}$ and oxidation of $\mathrm{H}_{2}$, i.e.,

$$
\begin{array}{lll}
\mathrm{H}_{2} \mathrm{O}+\mathrm{hv} & \rightarrow \mathrm{OH}+\mathrm{H} \\
\mathrm{O}(1 \mathrm{D})+\mathrm{H}_{2} & \cdots & \mathrm{OH}+\mathrm{H}
\end{array}
$$

$O\left({ }^{1} D\right)$ in turn results from the photolysis of the Martian ozone.

The catalytic oxidation of $\mathrm{CO}$ detailed in the set of reactions R6-R9 requires a large value of the eddy diffusion coefficient, exceeding $10^{8} \mathrm{~cm}^{2} \mathrm{~s}^{-1}$ in the middle atmosphere, i.e., around 30-40 km altitude (McElroy and Donahue, 1972). This permits a rapid downward transport of $\mathrm{CO}$ to the region where the $\mathrm{OH}$ abundance is large. It also prevents an excessive build-up of atomic oxygen densities above $25 \mathrm{~km}$ since below this altitude $O$ atoms quickly recombine to yield $\mathrm{O}_{2}(\mathrm{R} 2)$. While large $\mathrm{K}$ in the middle atmosphere is needed for this mechanism to work, only moderate amounts of water vapor are called for. A maximum of a few tens of precipitable microns of $\mathrm{H}_{2} \mathrm{O}$ is adequate $\left(1\right.$ pr $\mu \mathrm{m}$ of $\mathrm{H}_{2} \mathrm{O}=10^{-4} \mathrm{gm}$ $\mathrm{H}_{2} \mathrm{O} / \mathrm{cm}^{2}$, or $3.35 \times 10^{18} \mathrm{H}_{2} \mathrm{O}$ molecules $\mathrm{cm}^{-2}$, i.e., $\mathrm{H}_{2} \mathrm{O} / \mathrm{CO}_{2}$ $\approx 15 \mathrm{ppm}$ for uniformly mixed $\mathrm{H}_{2} \mathrm{O}$ ). The water vapor 
abundance required in this mechanism is still greater than the observed globally and annually averaged value, which is 10 $15 \mathrm{pr} \mu \mathrm{m}$ or $150-225 \mathrm{ppm}$ (Jakosky and Farmer, 1982). The more serious difficulty, however, is the extremely large $K$ needed in the $30-40 \mathrm{~km}$ range.

Large values of $\mathrm{K}$ on the order of $2 \times 10^{7-4 \times 10^{9} \mathrm{~cm}^{2} \mathrm{~s}-1}$ have been inferred for the upper atmosphere of Mars $(100 \mathrm{~km}$ $<\mathbf{z}<170 \mathrm{~km}$ ) from a comparison of the Viking measurements of $\mathrm{CO}, \mathrm{O}, \mathrm{N}_{2}$ and $\mathrm{Ar}$ densities with photochemical models (Nier and McElroy, 1977). However, there is no observational or theoretical evidence for large values of $K\left(\geq 10^{8} \mathrm{~cm}^{2} \mathrm{~s}^{-1}\right)$ in the non-dusty, middle atmosphere of Mars, outside of the dust storms. Instead, recent analysis of the Martian hazes yields relatively low values of $K$ in the middle atmosphere. Kahn (1989) has analyzed the Viking Orbiter limb images in conjunction with the relevant thermal structure data from the Infrared Thermal Mapper (IRTM) and the Mars Atmosphere Water Detector (MAWD) data to determine the distribution of hazes in the Mars atmosphere. The analysis depends on two critical parameters: mixing time, hence $K$, and the size and density distributions of the haze particles. Kahn calculates $K$ on the order of $10^{5} \mathrm{~cm}^{2} \mathrm{~s}^{-1}\left(4-9 \times 10^{4} \mathrm{~cm}^{2} \mathrm{~s}^{-1}\right)$ in the region of the hazes, which extend from 20 to $80 \mathrm{~km}$ altitude in his analysis. These observations correspond to a relatively clear Martian atmosphere, with vertical optical depth of dust $<0.4$ at the surface.

\section{Mechanism 2: Moderate $\mathrm{K}$, large $\mathrm{H}_{2} \mathrm{O}$ (Parkinson and Hunten, 1972)}

This scenario for recycling $\mathrm{CO}_{2}$ also involves catalytic oxidation of $\mathrm{CO}$. However, the constraints on $\mathrm{K}$ are relaxed somewhat. The source of hydroxyl radicals in this mechanism is principally hydrogen peroxide, and the main chemical scheme is as follows:

$$
\begin{array}{lll}
\mathrm{HO}_{2}+\mathrm{HO}_{2} & ---> & \mathrm{H}_{2} \mathrm{O}_{2}+\mathrm{O}_{2} \\
\mathrm{H}_{2} \mathrm{O}_{2}+\mathrm{hv} & --\rightarrow & \mathrm{OH}+\mathrm{OH}
\end{array}
$$

followed by R6 and R7

$$
\begin{array}{lll}
2(\mathrm{CO}+\mathrm{OH} & -\cdots & \left.\mathrm{CO}_{2}+\mathrm{H}\right) \\
2\left(\mathrm{H}+\mathrm{O}_{2}+\mathrm{M}\right. & \cdots & \left.\mathrm{HO}_{2}+\mathrm{M}\right)
\end{array}
$$

$\mathrm{Net} \quad 2 \mathrm{CO}+\mathrm{O}_{2}+\mathrm{h} v \quad---->2 \mathrm{CO}_{2}$

For this recycling mechanism, $K$ of $-5 \times 10^{6} \mathrm{~cm}^{2} \mathrm{~s}^{-1}$ in the $30-$ $40 \mathrm{~km}$ region of Mars is required. Although smaller than in the previous mechanism, it is still large. The major difficulty with this model, however, lies in the fact that it requires the Martian atmosphere to be essentially 'wet', with water vapor mixing ratios approaching $1000 \mathrm{ppm}$, which are far in excess of the average value of $150-225 \mathrm{ppm}$. A variation of this second recycling mechanism, involving the hydrogen peroxide source of $\mathrm{OH}$, requires an acceptable $\mathrm{H}_{2} \mathrm{O}$ abundance of 12.5 pr $\mu \mathrm{m}(-200 \mathrm{ppm})$ but a $\mathrm{K}$ value of $\sim 5 \times 10^{7} \mathrm{~cm}^{2} \mathrm{~s}^{-1}$ in the $30-$ $40 \mathrm{~km}$ range on Mars (Kong and McElroy, 1977). In fact, $K$ in this version depends critically on the rate constant $k_{15}$ of the reaction

$$
\mathrm{HO}_{2}+\mathrm{OH} \longrightarrow \mathrm{H}_{2} \mathrm{O}+\mathrm{O}_{2}
$$

with $\mathrm{k}_{15}=1 \times 10^{-11} \mathrm{~cm}^{3} \mathrm{~s}^{-1}$ assumed by Kong and McElroy. The currently accepted value of $k 15$ is a factor of 14 to 18 greater (for $175 \mathrm{~K}<\mathrm{T}<200 \mathrm{~K}$ in the middle atmosphere of Mars, with $\mathrm{k}_{15}=1.7 \times 10^{-11} \exp (416 / \mathrm{T})$ [Warneck, 1988], which would require correspondingly greater values of $\mathrm{K}$ of $\left(\sim 10^{9}\right.$ $\mathrm{cm}^{2} \mathrm{~s}^{-1}$ ) in the $30-40 \mathrm{~km}$ region for the Kong and McElroy model to work.
In summary, neither of the abovementioned gas phase mechanisms for recycling Martian $\mathrm{CO}_{2}$ are satisfactory, as they require either unacceptably large values of $K$ in the middle atmosphere, or an unacceptably large water vapor abundance, or both. As an alternative, we propose that the catalytic oxidation of carbon monoxide occurs instead as a heterogeneous chemical process on aerosols, most likely on ice aerosols, in the atmosphere of Mars. This hypothesis is further strengthened by the observed depletion of carbon monoxide in the middle atmosphere of Mars. In the following we first discuss the evidence concerning aerosols and the observation of the $\mathrm{CO}$ depletion, and then the relevant heterogeneous chemistry.

\section{Evidence of Aerosols and Carbon Monoxide Hole}

\section{Aerosols}

The most recent detection of aerosols in the atmosphere of Mars has been obtained with the Auguste Spectrophotometer Interferometer on board the Phobos 2 spacecraft (Blamont, et al., 1989; Krasnopolsky, et al., 1989). Between early February and late March, 1989, the Auguste instrument recorded the occultation of the sun by Mars on 32 orbits in the ultraviolet (2200-3200 $\AA$ ), visible (two channels: $7600 \AA$ and $9400 \AA$ ) and infrared (two channels: 1.87 and $3.7 \mu \mathrm{m}$ ). Furthermore, the well defined spectral characteristics of the stray light between 3200 and $5200 \AA$ were exploited to obtain additional atmospheric information, including composition of the aerosol particles. The observed behavior of the UV-visible occultation light curves has been interpreted to imply the presence of aerosols up to at least an altitude of $40-50 \mathrm{~km}$. The extinction of UV light by these particles is discemable down to a wavelength of $2500 \AA$, with a provisional value of their optical depth on the order of $10^{-4}$ per kilometer. The observations indicate two types of particies -- water ice at high altitudes, and dust (some form of iron oxide, magnetite/hematite, etc.) at lower altitudes. The IR channels at 1.85 and $3.7 \mu \mathrm{m}$ also show evidence of solid particles which could be composed of either water ice or basalt-limonite. In either the UV-visible or the IR analysis, the water ice could be contaminated with dust or other material. Also, both Auguste and the Infrared Spectrometer (ISM) measurements yield low water mixing ratios of a few times $10^{-5}$, as would be expected for the equatorial region during the northern spring equinax time period of the Phobos mission.

Ample evidence of suspended dust aerosols in the atmosphere of Mars has been provided by previous observations, such as those from Mariner 9 (Anderson and Leovy, 1978) and the Viking missions (Pollack, et al., 1979; Jaquin, et al., 1986). In addition, water ice aerosol layers were detected between 20 and $70 \mathrm{~km}$ by Mars 5 instruments (Krasnopolsky, et al., 1979), and both Pollack, et al. (1979) and Jaquin, et al. (1986) supported the presence of two types of aerosols -- water ice above and dust below. The most comprehensive study of aerosol temporal and spatial variations has been given by Jaquin, et al. (1986), based on an analysis of 100 Viking Orbiter images with a vertical resolution of 1.5 $\mathrm{km}$. They find numerous haze layers between 30 and $90 \mathrm{~km}$, depending on season, and consisting of water ice. Kahn (1989) also finds evidence of discrete ice haze layers between 20 and $80 \mathrm{~km}$. In both analyses, a continuous haze of the Martian red dust is found to extend from below the ice hazes to the ground. The diumal behavior of the atmospheric optical depths derived from the Viking lander camera images also gives evidence of water ice particles to relatively high altitudes in the Martian atmosphere (Colburn, et al., 1989).

From the observations done in the 1970's (Viking, Mariner 9, Mars 5) and in 1989 (Phobos), it is apparent that aerosols consisting of mainly water ice are distributed to high altitudes in the Martian atmosphere. These water ice particles 
could be doped with some contaminants such as dust, etc.; in the lower atmosphere the aerosols are composed mostly of dust. In addition, the existence of ice aerosols and their microphysical properties are strictly governed by the atmospheric temperature structure and so the distribution of ice aerosols would be expected to show temporal, seasonal and spatial variations in the atmosphere of Mars.

\section{Co Hole}

A related observation which provides support for the proposed heterogeneous chemistry in the Martian atmosphere is the Phobos/ISM observation of CO at $2.35 \mu \mathrm{m}$ on Olympus Mons, Pavonis Mons and Ascraeus Mons. These observations indicate a depletion of $\mathrm{CO}$ in the $14-26 \mathrm{~km}$ range (Drossart, et al., 1989) with a CO mixing ratio of $2.5 \times 10^{-4}$ being marginally consistent with the ISM data. Although, because of the nature of this experiment, $\mathrm{CO}$ is not measured above $26 \mathrm{~km}$, the inferred depletion is found to be independent of the $\mathrm{CO}$ mixing ratio assumed above $26 \mathrm{~km}$. Larger mixing ratios give a poorer fit. The ISM value in the $14-26 \mathrm{~km}$ height range is approximately a factor of 3 smaller than the currently accepted "globally averaged" CO mixing ratio on Mars.

\section{Heterogeneous Chemistry on the Martian Aerosols}

It is proposed that aerosols catalyze the reaction between $\mathrm{CO}$ and $\mathrm{O}$ to recycle carbon dioxide on Mars, i.e.,

$$
\mathrm{CO}+\mathrm{O} \stackrel{\text { aerosols }}{-} \mathrm{CO}_{2}
$$

As noted earlier, the homogeneous gas phase reaction, $\mathbf{R} 3$ is spin forbidden. Its rate is (Wameck, 1988).

$$
\begin{aligned}
\mathrm{k} 3 & =2.6 \times 10^{-37} \mathrm{~cm}^{6} \mathrm{~s}^{-1} \\
& =9.2 \times 10^{-38} \mathrm{~cm}^{6} \mathrm{~s}^{-1}
\end{aligned}
$$

at $200 \mathrm{~K}$ at $170 \mathrm{~K}$

(170K and $200 \mathrm{~K}$ approximately bracket the range of temperature in the region of ice aerosols on Mars). The corresponding 2-body rate constant (Warneck, 1988) for the middle atmosphere of Mars, considering $\mathrm{CO}_{2}$ as the background gas, is

$$
\begin{aligned}
\mathrm{k}^{\prime} 3 & =5.2 \times 10^{-20} \mathrm{~cm}^{3} \mathrm{~s}^{-1} \\
& =2.0 \times 10^{-21} \mathrm{~cm}^{3} \mathrm{~s}^{-1}
\end{aligned}
$$

at $200 \mathrm{~K}$ at $170 \mathrm{~K}$

If the heterogeneous chemical reaction involving aerosols as catalysts is to compete with the previously proposed $\mathrm{OH}$ catalysis mechanism for recycling $\mathrm{CO}_{2}$, their rate constants should be comparable. The $\mathrm{HO}_{\mathrm{x}}$ catalysis reaction $\mathrm{R} 6$ has a rate constant

$$
\mathrm{k}_{6}=1.4 \times 10^{-13} \mathrm{~cm}^{3} \mathrm{~s}^{-1}
$$

in the context of the Mars atmosphere (Shimazaki, 1981). A comparison between $\mathrm{k}^{\prime} 3$ and $\mathrm{k}_{6}$ shows that the rate constant for the proposed heterogeneous chemical process catalyzed by aerosols, R16, would need to have a rate constant roughly (370) $\times 106$ greater than the corresponding values in the homogeneous gas phase to be significant. This increase, however, represents an upper limit, as the required increase in the rate constant is expected to be far less once all the sources and sinks of $\mathrm{CO}_{\mathrm{x}}, \mathrm{O}_{\mathrm{x}}, \mathrm{HO}_{\mathrm{x}}$, etc. from the ionosphere down to the surface are included.

Laboratory measurements of the rate constant of the relevant heterogeneous chemical reaction $\mathrm{R} 16$ are not yet available. However, a possible analog might exist in the terrestrial Antarctic ozone hole problem, especially when one considers the observed depletion in the Martian CO.

The depletion of ozone in the $12-25 \mathrm{~km}$ region in the Antarctic spring is believed to be the result of heterogeneous chemistry catalyzed by water ice particles of the Polar
Stratospheric Clouds (PSC) present in the same altitude region in winter (Solomon, et al., 1986). Contamination of water ice with $\mathrm{HCl}$ is found to accelerate the process. The depletion is caused by the reaction of free chlorine radicals with ozone in the spring time. Chlorine, however, is sequestered in a benign compound, chlorine nitrate, $\mathrm{ClONO}_{2}$, in the winter time. The homogeneous gas phase reaction between $\mathrm{ClONO}_{2}$ and water vapor or $\mathrm{HCl}$ is extremely slow, i.e.,

$$
\begin{aligned}
& \mathrm{ClONO}_{2}+\mathrm{H}_{2} \mathrm{O} \longrightarrow \mathrm{HOCl}+\mathrm{HNO}_{3} \\
& \mathrm{ClONO}_{2}+\mathrm{HCl} \longrightarrow \mathrm{Cl}_{2}+\mathrm{HNO}_{3}
\end{aligned}
$$

with $\mathrm{k}_{17}<3.4 \times 10-21 \mathrm{~cm}^{3} \mathrm{~s}^{-1}$ and $\mathrm{k}_{18}<8.4 \times 10-21 \mathrm{~cm}^{3} \mathrm{~s}^{-1}$ (Hatakeyama and Leu, 1986)

These rates are of the same order, or slower, than the one for the Martian analog, $\mathbf{k}^{\prime} 3$.

In the presence of PSC water ice particles, the rates of the $\mathrm{ClONO}_{2}$ reactions increase dramatically. (This would result in a large production of $\mathrm{Cl}_{2}$ and $\mathrm{HOCl}$, both of which are photodissociated in the Antarctic spring, producing free chlorine, which in turn attacks ozone.) In fact, they are expected to rise to $2 \times 10^{-14} \mathrm{~cm}^{3} \mathrm{~s}^{-1}$, as needed to explain the observed depletion in ozone (Solomon, et al., 1986). Thus, an increase in the rate constants by at least six to seven orders of magnitude from homogeneous gas phase to heterogeneous catalysis reactions is entirely feasible. The proposed heterogeneous chemical process for Mars does not call for unrealistic increases in the rate constants.

In the absence of proper laboratory data on sticking coefficients and rate constants, it is not at this time possible to say whether the chemical analogy of the Antarctic ozone hole has a true parallel in the proposed heterogeneous process on Mars, or whether the aerosols simply serve as 'surfaces' for the heterogeneous process. Depending upon the composition of the ice particles (i.e., the nature of the dissolved contaminants), it is possible that $\mathrm{CO}$ and $\mathrm{O}$ could actually participate chemically with the constituents in the Martian ice aerosols, or form hydrates, etc. and trigger subsequent chemical reactions to release $\mathrm{CO}_{2}$. It should also be mentioned that the suspended dust particles would most likely serve as condensation nuclei for the ice particles. The possibility of 'dirty' ice aerosols exists, given the preponderance of suspended dust in the Mars atmosphere much of the time, but even if the dust were confined to aerosol interiors, possible diffusion of $\mathrm{CO}, \mathrm{O}$, etc. in the ice lattice could permit direct interaction with the $\mathrm{Si}+2, \mathrm{Fe}^{+3}, \mathrm{Mg}^{+2}$, etc. ions of the dust, and so could play an important role in the heterogeneous catalysis. Other possibilities for the dissolved contaminants are $\mathrm{HCl}, \mathrm{HNO}_{3}, \mathrm{H}_{2} \mathrm{SO}_{4}$, etc. $\mathrm{HCl}$ and $\mathrm{HNO}_{3}$ have not yet been detected, but cannot be ruled out on theoretical grounds. The upper limit to $\mathrm{SO}_{2}$ (pre-cursor to $\mathrm{H}_{2} \mathrm{SO}_{4}$ formation) from the Phobos/Auguste $2800 \AA$ transmission data is $0.1 \mathrm{ppm}$, and its presence may require recent volcanic activity on Mars, but its presence is not likely to increase the probability of heterogeneous catalysis substantially. In summary, despite the lack of available laboratory data, the possibility of chemical reactions involving dissolved constituents in the Martian ice aerosols, combined with the similarities in the required rate constants, the importance of ice particles as catalysts, the similarities in aerosol atmospheric opacities, size distributions and environmental temperatures, and possible similarities in the relevant time constants for the CO depletion on Mars (see below) and the ozone hole on Earth, all hint at a possible chemical analog of the Antarctic heterogeneous process in the atmosphere of Mars.

Support for ice aerosols, pure or doped, as the likely catalyst in the proposed heterogeneous chemistry on Mars is provided by the observed depletion in CO from approximately $14 \mathrm{~km}$ to at least $26 \mathrm{~km}$ altitude. The heterogeneous reaction 
R16 on aerosols would also result in the loss of $\mathrm{CO}$. The behavior of the $\mathrm{CO}$ depletion, however, necessitates that the process essentially cease at lower elevations on Mars. This would be consistent with the heterogeneous chemistry occurring on the ice particles, as they are confined mostly to higher elevations, while in the lower atmosphere, the aerosols are composed of mainly dust. Furthermore, the sticking coefficients are found to decrease with increasing temperatures, further restricting the proposed heterogeneous chemistry to higher elevations, where the aerosols are mainly composed of ice particles.

Since the ice aerosols vary temporally and spatially, such variation is expected to be reflected in the (height) distribution of $\mathrm{CO}$ as well. Although the globally averaged photochemical lifetime of $\mathrm{CO}$ in the Mars atmosphere is 3 years, heterogeneous chemistry could readily reduce it to the order of a few days, or less. This is analogous to the situation in the Antarctic ozone hole problem, in which the ozone lifetime is reduced through heterogeneous chemistry to a few days to few weeks from its (homogeneous gas phase) photochemical lifetime of $\sim 10$ years in the stratosphere. Thus, globally averaged measurements of the Martian $\mathrm{CO}$ can easily mask the existence of local 'anomalies' in the $\mathrm{CO}$ mixing ratio such as those recorded by Phobos/ISM. In this regard, it is also important to point out that eddy mixing alone may not result in a uniform vertical distribution of $C O$ since $K \sim 105 \mathrm{~cm}^{2} \mathrm{~s}^{-1}$ in the region of the ice hazes (where the proposed heterogeneous chemistry occurs) would yield a mixing time constant of about 100 days which is most likely longer than the lifetime of the CO hole.

\section{Conclusion}

In view of the extensive observational evidence regarding aerosols in the atmosphere of Mars, and the difficulties of high mixing rates and high water abundances in previously suggested mechanisms for the stability of Martian $\mathrm{CO}_{2}$, it is proposed that oxidation of carbon monoxide catalyzed by aerosols could play a significant role in recycling $\mathrm{CO}_{2}$ on Mars. The same heterogeneous chemical process could also result in short term temporal and spatial variations in the vertical distribution of Martian carbon monoxide, although its globally and seasonally averaged mixing ratio may not be affected significantly. It is further suggested that the aerosols most effective in the heterogeneous chemistry are the ice aerosols. Laboratory measurements of sticking coefficients, adsorption, diffusion and re-emission properties, and rate constants -- mainly involving $\mathrm{CO}$ and $\mathrm{O}$ (but possibly also $\mathrm{NO}_{\mathrm{x}}, \mathrm{HNO}_{\mathrm{X}}, \mathrm{HCl}$, etc.) over aerosols (pure and contaminated $\mathrm{H}_{2} \mathrm{O} \mathrm{O}$-ice, Martian dust, and possibly $\mathrm{CO}_{2}$-ice) under the Martian environmental conditions -- are needed to test the validity of the proposed hypothesis of heterogeneous chemistry in the atmosphere of Mars. Additional constraints are also needed on the size and density distributions of the aerosols (ice and dust) to evaluate whether the aerosols can simply act as surfaces for impact reactions in the atmosphere of Mars.

Acknowledgments. Critical review of the manuscript by J. Bishop, T. Donahue, P. Drossart, D. Hunten, R. Kahn, C. Leovy, L. Stief and several anonymous referees was extremely beneficial. S. K. Atreya acknowledges support received from NASA Solar System Exploration Division under grant NAGW-1442.

\section{References}

Anderson, E. and C. B. Leovy, Mariner 9 limb observations of dust and ice hazes on Mars, J. Atmos. Sci., 35, 723, 1978.

Blamont, J. E., et al., Vertical profiles of dust and ozone in the Martian atmosphere deduced from the observation of solar occultations, Nature, 341, 600, 1989.

Colburn, D. S., J. B. Pollack, and R. M. Haberle, Diumal variations in optical depths at Mars, Icarus, 79, 159, 1989.

Drossart, P., et al., Martian atmospheric studies from the ISM experiment, paper presented at the International Symposium on Phobos Observations at Mars, Paris, France, 23-27 October, 1989.

Hatakeyama, S., and M. T. Leu, Reaction of chlorine nitrate with $\mathrm{HCl}$ and $\mathrm{H}_{2} \mathrm{O}$, Geophys. Res. Lett., 13, 1343, 1986.

Jakosky, B. M. and C. B. Farmer, Seasonal and global behavior of water vapor in the Mars atmosphere, $J$. Geophys. Res., 87, 2999, 1982.

Jaquin, F., P. Gierasch and R. Kahn, The vertical structure of limb hazes in the Martian atmosphere, Icarus, 68, 442, 1986.

Kahn, R, Ice, haze, snow and the Mars water cycle, $J$. Geophys. Res. (Red), submitted, 1989.

Kong, T. Y. and M , B. Mc Elroy, Photochemistry of the Martian atmosphere, Icarus, 32, 168, 1977.

Krasnopolsky, V. A., et al., Phobos 2: Solar occultation spectroscopic measurements of the Martian amosphere at 1.9 and 3.7 microns, Nature, 341, 603, 1989.

Leu, M. -T, Laboratory studies of sticking coefficients and heterogeneous reactions important in the Antarctic stratosphere, Geophys. Res. Lett., 15, 17, 1988.

McElroy, M. B., and T. M. Donahue, Stability of the Martian atmosphere, Science, 177, 986, 1972.

Nier, A. O., and M. B. McElroy, Composition and structure of the Mars upper atmosphere: results from the neutral mass spectrometers on Viking 1 and 2, J. Geophys. Res., 82, 4341, 1977.

Parkinson, T. D., and D. M. Hunten, Spectroscopy and aeroriomy of $\mathrm{O}_{2}$ on Mars, J. Atmos. Sci., 29, 1380, 1972.

Pollack, J. B., et al., Properties and effects of dust particles suspended in the Martian atmosphere, J. Geophys. Res., $84,2929,1979$.

Shimazaki, T., A model of temporal variations in ozone density in the Martian atmosphere, Planet. Space Sci., 29, 21,1981 .

Solomon, S., et al., On the depletion of Antarctic ozone, Nature, 324, 755, 1986.

Warneck, P. Chemistry of the Natural Atmosphere, Academic Press, 1988, pp, 725 and 733.

S. K. Atreya, Department of Atmospheric, Oceanic and Space Sciences, The University of Michigan, Ann Arbor, MI 48109-2143.

J. E. Blamont, Service d'Aeronomie du CNRS, B.P. No. 3, 91371 Verrieres-le-Buisson, Cedex, France.

(Received: November 6, 1989;

Revised: December 15, 1989;

Accepted: January 18, 1990) 